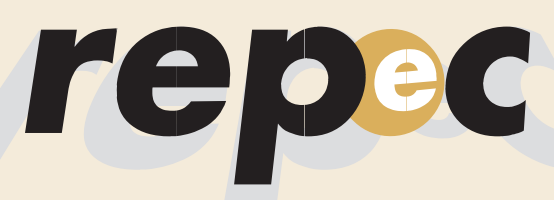

REPeC, Brasília, v. 9, n. 2, art. 6, p. 217-234, abr.jun. 2015 Disponível online em www.repec.org.br DOI: http://dx.doi.org/10.17524/repec.v9i2.1231
Revista de Educação e Pesquisa em Contabilidade Journal of Education and Research in Accounting Revista de Educación e Investigación en Contabilidad

Periódico Trimestral, digital e gratuito publicado pela Academia Brasileira de Ciências Contábeis

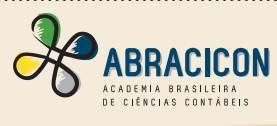

\title{
Análise das Opiniões Emitidas nas Cartas-Comentários sobre o Termo Prudence
}

\section{Resumo}

Desde 2001, o International Accounting Standards Board (Iasb) tem feito esforços para a revisão da Conceptual Framework ou Estrutura Conceitual (EC). Para tanto, emitiu os Discussion Papers (DP), objetivando coletar opiniões dos interessados em Contabilidade sobre diversos aspectos da EC. Entre os pontos discutidos, tem-se a inclusão, ou não, da Prudência na EC. Portanto, este estudo objetiva analisar as opiniões emitidas nas cartas-comentários em resposta aos DPs de 2006 e 2013 acerca da exclusão do termo Prudência da EC. A pesquisa foi realizada pela análise de conteúdo de 420 cartas-comentários (Comment Letters) encaminhadas ao Iasb, sendo identificadas 176 que contêm os termos Prudence/Conservatism, em que 117 dessas são a favor da inclusão do termo. Entre aqueles contrários à inserção, a justificativa prevalecente é a existência do conflito entre Prudência e neutralidade. As opiniões dos respondentes também foram segregadas por localidade e grupos de interesses, constatando que os respondentes europeus são mais favoráveis à inclusão do termo, enquanto que a América Anglo-Saxônica é o que menos defende. No que diz respeito aos grupos de interesses, o que mais se mostrou a favor da inserção do termo foram os Preparadores, enquanto que as Instituições Financeiras foram os agentes mais desfavoráveis. Utilizando a Análise

Kappa, observou-se que o grau de concordância de opinião entre os respondentes indica uma concordância fraca ao total das amostras, sugerindo que é preciso maior debate e reflexão sobre o tema.

Palavras-chave: Estrutura Conceitual, Prudência, Informação Contábil, Cartas-Comentários.
Victor Ranieri Bomfim

Sampaio de Araújo

Bacharel em Ciências Contábeis pela UFAL

Mestrando no Programa Multi-institucional e Inter-regional de Pós-Graduação em Ciências Contábeis UnB/UFPB/UFRN UFPB - CCSA - Programa de PósGraduação em Ciências Contábeis. Contato: Cidade Universitária, João Pessoa, PB, Brasil, CEP: 58.051-900. E-mail: ranieri.victor@gmail.com

Ana Karla de Lucena Gomes Bacharela em Ciências Contábeis pela UFPB Mestrando no Programa Multiinstitucional e Inter-regional de PósGraduação em Ciências Contábeis UnB/ UFPB/UFRN UFPB - CCSA - Programa de Pós-Graduação em Ciências Contábeis. Contato: Cidade Universitária, João Pessoa, PB, Brasil, CEP: 58.051-900. E-mail: aklucenagomes@gmail.com

Wenner Glaucio Lopes Lucena Doutor em Ciências Contábeis pela UnB/ UFPB/UFRN Professor da Universidade Federal da Paraíba - UFPB CCSA Programa de Pós-Graduação em Ciências Contábeis. Contato: Cidade Universitária, João Pessoa, PB, Brasil, CEP: 58.051-900. E-mail: wdlucena@yahoo.com.br

\section{Edilson Paulo}

Doutor em Ciências Contábeis pela USP Professor da Universidade Federal da Paraíba - UFPB CCSA - Programa de Pós-Graduação em Ciências Contábeis. Contato: Cidade Universitária, João Pessoa, PB, Brasil, CEP: 58.051-900. E-mail: e.paulo@uol.com.br 


\section{Introdução}

Os usuários externos não são participantes ativos da gestão cotidiana das entidades. Enquanto os gestores possuem facilidade em acessar qualquer informação para uma melhor decisão, os fornecedores de capital colocam-se em uma posição desvantajosa em relação aos primeiros. Com a tentativa de eliminar essa assimetria informacional, as empresas elaboram e divulgam periodicamente Relatórios Contábil-Financeiros de propósito geral, cujo objetivo é fornecer informações contábil-financeiras que sejam úteis a investidores existentes e em potencial, a credores por empréstimos e a outros credores, quando da tomada de decisão ligada ao fornecimento de recursos para a entidade (Comitê de Pronunciamentos Contábeis [CPC], 2011).

Dessa maneira, o Conservadorismo seria uma forma de tentar minimizar "possíveis comportamentos oportunísticos dos gestores" (Teixeira, Costa \& Galdi, 2009, p. 81). O Conservadorismo versa em um elemento presente há tempos nos modelos contábeis e consiste na Prudência, que corresponde à utilização da cautela quando incertezas estiverem envolvidas, de maneira que os fornecedores de capital das empresas (investidores e credores) sejam resguardados (Watts, 2003). Destaca-se que ser prudente refere-se apenas a uma postura mediante às incertezas inerentes ao modelo em que não requer a omissão de ativos e reconhecimento de passivos indiscriminadamente, uma vez que, dessa forma, a informação não seria neutra (Teixeira et al., 2009).

O conceito de Prudência está descrito no parágrafo 37 Framework for the Preparation and Presentation of Financial Statements do Internacional Accounting Standards Board (Iasb), uma vez que tal documento divulgava a ideia de que o exercício da Prudência não é, necessariamente, contraditório à neutralidade. No ano de 2010 o Iasb publicou o Capítulo 1 - The objective of general purpose financial reporting - e Capítulo 3 Qualitative characteristics of useful financial information - da Estrutura Conceitual para relatórios financeiros, fruto de um trabalho conjunto desenvolvido com o Financial Accounting Standards Board (Fasb), em que, no desenvolvimento do Capítulo 3, retirou-se as alusões ao conceito de Prudência (International Accounting Standards Board [IASB], 2013).

A justificativa para a retirada do termo Prudência da EC seria a inconsistência com a neutralidade, além disso, afirma que subestimar os ativos ou superestimar os passivos resolutamente em um período, conduz, comumente, a superavaliar o desempenho financeiro em períodos futuros. Muitos interessados têm-se mostrado preocupados com a remoção do termo Prudência da EC, alegando, entre outros aspectos, que ser conservador pode ser necessário a fim de eliminar implicações de uma possível estimativa demasiadamente otimista por parte da administração da entidade (IFRS, 2013).

Para a revisão da EC, o Iasb divulgou dois Discussion Papers a fim de coletar a opinião do público interessado sobre alguns pontos na revisão da EC e de suas normas. O primeiro Discussion Paper (DP), emitido em 2006, resultou na Conceptual Framework for Financial Reporting de 2010. O segundo DP, emitido no ano de 2013, ainda se encontra em processo de desenvolvimento. Entre as indagações observadas ao longo dos dois DPs, encontra-se o questionamento sobre a retirada do termo Prudência.

Considerando o exposto e a oportunidade que o Iasb abre para o feedback, a pesquisa tem como objetivo analisar, comparativamente, as opiniões emitidas por meio das cartas-comentários sobre a Estrutura Conceitual de 2006 e 2013, emitidas pelos grupos de interesses na Contabilidade, no que se refere à exclusão do termo Prudência da EC para Relatórios Financeiros do Iasb. Agora, em 2015, está em discussão o Exprosure Draft em que o Iasb esclarece o principal papel em torno da Prudência (IFRS, 2015).

A pesquisa busca contribuir com o debate acerca da Prudência na EC, por meio da análise das opiniões emitidas pelos operadores da contabilidade, analisando se de fato há insatisfações quanto à exclusão do termo Prudência e se as contestações podem vir, ou não, a culminar em alterações na EC. Adicionado a isso, permite-se verificar se as opiniões dos usuários mudaram ao longo do tempo, ao analisar, comparativamente, as cartas enviadas em resposta ao DP emitido em 2006 e ao DP emitido em 2013.

Presume-se que a discussão abordada no presente estudo auxilie a realização de novas pesquisas, com vistas a explorar outros aspectos contidos nesses documentos, uma vez que o estudo restringiu-se em avaliar apenas as cartas-comentários enviadas ao Iasb, como resposta aos DPs referentes aos anos de 2006 e 2013. 


\section{Revisão da Literatura}

\subsection{Estrutura conceitual para relatórios financeiros}

No que tange ao processo de elaboração das demonstrações financeiras, verifica-se que é necessário estabelecer um alicerce que forneça o embasamento necessário para esta referida elaboração. Sobretudo, se observado que a maioria desses usuários da contabilidade são usuários externos, que não possuem participação quando da elaboração das demonstrações, nem poder de escolha sobre qual o auditor irá examinar as demonstrações financeiras (Paulo, 2002). Com isso, surge a necessidade de desenvolvimento de pilares norteadores que sejam considerados, por todos os elaboradores das demonstrações contábeis, como um elemento em comum, com a finalidade de proporcionar a harmonização quando na elaboração das informações e, consequentemente, comparabilidade, a fim de garantir escolhas adequadas de reconhecimento, mensuração e divulgação, em uma tentativa de proporcionar uma informação mais adequada com a realidade.

Segundo Godfrey, Hodgson, Holmes e Tarca (2010, p. 94), órgãos reguladores e acadêmicos da Contabilidade se empenharam para elaborar uma EC que pudesse proporcionar uma "declaração definitiva sobre a natureza e a finalidade da contabilidade financeira e emissão de relatórios e que fornece orientação para toda a prática".

Vatter (1964, p. 6 como citado em Paulo, 2002) afirma que "toda Ciência, metodologia ou outro corpo de conhecimento é orientado por alguma estrutura conceitual", o que não é diferente para os relatórios contábil-financeiro. Dessa forma, buscou-se o desenvolvimento de uma EC para relatórios financeiros, que pudesse servir como elemento norteador para elaboração das demonstrações contábeis, bem como para elaboração de normas.

Neste contexto, Deegan e Unermam (2011) afirmam que na falta de uma teoria aceita, as normas vão sendo desenvolvidas isoladamente, ou seja, para uma finalidade específica. Isso as tornam vulneráveis a conter elementos divergentes entre si, uma vez que, não tiveram como base um mesmo documento norteador. O que pode ser observado nas estruturas aceitas é que estas possuem uma posição submissa e as normas específicas prevalecem, resultando na perda da força e sentido da EC. Dessa forma, divergências são encontradas, como a própria retirada da Prudência, que permanece presente na maioria das normas (Gebhardt, Mora, \& Wagenhofer, 2014).

Destacam-se, atualmente, duas estruturas conceituais para elaboração das demonstrações financeiras: (1) a Estrutura Conceitual do Fasb e (2) a Estrutura Conceitual do Iasb.

\subsection{Estrutura conceitual para relatórios financeiros Fasb}

Na busca por uniformidade e eliminação de procedimentos alternativos na Contabilidade, surgiu a necessidade do desenvolvimento de um conjunto de instrumentos reguladores, e, com isto, uma EC das demonstrações contábil-financeira. A discussão para o desenvolvimento de uma EC inicia-se nos Estados Unidos da América (EUA). Segundo, Zeff (1999), as primeiras tentativas de desenvolver uma "estrutura conceitual", na literatura contábil dos EUA ficaram por incumbência de William A. Paton e John B. Canning.

O professor William Paton, diretor de pesquisa do American Association of Accountants (AAA) publicou em sua tese de doutoramento, sob o título Accounting Theory de 1922, seis postulados, que são considerados pelo referido autor como sendo as premissas básicas da contabilidade, entre eles, a continuidade da entidade (Hendriksen \& Van Breda, 1999). Juntamente com Paton e Canning (1929 como citado em Zeff \& John, 2000) o professor foi o primeiro a desenvolver e apresentar uma EC para avaliação de ativos e mensuração do lucro, em seu trabalho The Economics of Accountancy. Sendo assim, esses trabalhos influenciaram muitos outros escritores ao longo dos anos (Zeff \& John, 2000). O Fasb, por exemplo, até hoje cita em memorandos de discussão as definições de ativos e passivos trazidas por Canning (Hendriksen \& Van Breda, 1999). 
No ano de 1936, foi emitido pelo Comitê Executivo da AAA e publicado na The Accounting Review, a primeira tentativa institucional para estabelecer as bases de uma EC, a Tentative Statement of Accounting Principles Affecting Corporate Reports (Zeff, 1999). Nesse mesmo ano, foi organizado o Committee on Accounting Procedures (CAP), cuja finalidade constituía em delinear as propostas do American Institute of Accountants (AIA), sobre os Princípios de Contabilidade Generalizadamente Aceitos, por meio da emissão dos Accounting Research Bulletins (ARBs) entre os anos 1953 e 1959, sendo estes considerados as primeiras séries documentadas de princípios contábeis americanos (Paulo, 2002).

Em 1938, os professores Sanders, Hatfield e Moore publicaram A Statement of Accounting Principles, que demonstrava regras e princípios a serem observados quando na elaboração e divulgação dos balanços e demonstrações do resultado. Também nesse trabalho, os autores abordaram brevemente a respeito das convenções conceituadas como práticas sólidas implícitas quando da elaboração das demonstrações, como, por exemplo, o conceito de uma empresa em funcionamento (Hendriksen \& Van Breda, 1999). Em 1940, AAA publicou o trabalho An Introduction to Corporate Accounting Standards, dos autores Paton e Littleton, que expõe acerca do modelo de precificação baseado no custo histórico, amplamente aceito nos Estados Unidos (Zeff, 1999). Quando em 1948, também publicou sua revisão, que denominou de Accounting Concepts and Standards (Hendriksen \& Van Breda, 1999).

Em 1958, a American Institute of Certified Public Accountants (AICPA) organizou um comitê especial de pesquisa com o propósito de estudar como a prática da Contabilidade deveria ser mais bem organizada. O referido comitê propôs a criação do Accounting Principles Board (APB) para substituir o CAP, além de uma divisão de pesquisa em Contabilidade para auxiliá-lo, e, em 1959, procedeu-se à referida substituição. O supracitado Comitê destacou quatro níveis em que a Contabilidade deve ser abordada. São eles a saber: 1) postulados; 2) princípios; 3) regras ou 4) outros guias para a aplicação de princípios a situações específicas e pesquisa (Zeff, 1999).

Quanto ao termo "postulados", este não era comumente usado na literatura contábil. O comitê de pesquisa declarou que são poucos os postulados e correspondem aos pressupostos básicos sobre os quais os princípios estão alicerçados, ou seja, os princípios necessitam ser elaborados tomando-os por base (Zeff, 1999). Verifica-se que os postulados são provenientes da atmosfera econômica, política e tradições da sociedade de negócios. Portanto, a divisão de pesquisa priorizou os estudos voltados aos postulados e princípios gerais de Contabilidade, uma vez que os supracitados estudos serviram de base para os pronunciamentos futuros sobre Contabilidade do Instituto. "Dessa forma, surgiu o primeiro programa institucional para estabelecer uma EC - na qual princípios baseiam-se em postulados - embora o termo "estrutura conceitual" não tenha entrado em vigor até os anos 1970" (Zeff, 1999, p. 93).

Portanto, em 1961, foi produzido por Maurice Moonitz - primeiro diretor de pesquisa do referido comitê - o Estudo de Pesquisa em Contabilidade número 1 (ARS 1), intitulado, The Basic Postulates of Accounting, em que delineou os postulados básicos da contabilidade. Em seguida, em 1962, foi executado, também por Moonitz, juntamente com Robert T. Sprouse, o estudo de pesquisa em contabilidade número 3 (ARS 3), intitulado "A Tentative Set of Broad Accounting Principles for Business Enterprises", que tinha como objetivo abordar os princípios de contabilidade. Ambos os estudos foram rejeitados pela classe contábil, de maneira que foi encomendado a Paul Grady outro estudo para revisar os princípios contábeis existentes, cujo título foi Inventory of Generally Accepted Accounting Principles for Business Enterprises (ARS 7). Apesar da maior aceitação do ARS 7, quando comparado aos ARS 1 e 3, ele não atingiu o objetivo de explanar os princípios da contabilidade, de forma que os estudos em contabilidade continuaram a ser desenvolvidos de maneira $a d$ hoc., sendo incluído o conceito de Conservadorismo (Hendriksen \& Van Breda, 1999).

Segundo Hendriksen e Van Breda (1999), houve uma reprovação ao enfoque postulados/princípios. O professor William Vatter afirmou que em vez de postulados, o que deveria ser observado como elemento fundamental na elaboração de uma teoria da contabilidade eram os objetivos. Em resposta a esse ataque, foi produzido um documento intitulado A Statement of Basic Accounting Theory, conhecido pela sigla Asobat, emitido pela American Accounting Association (AAA) no ano de 1966. Esse foi o primeiro pronunciamento a orientar os usuários, e continha objetivos, padrões e diretrizes da Contabilidade. Esse trabalho contribuiu significativamente na direção de trabalhos seguintes, apesar de que este, assim como outros 
trabalhos, enfrentou a dificuldade que é estabelecer a conexão entre objetivos e princípios, principalmente se for levado em consideração que usuários são bastante heterogêneos (Hendriksen \& Van Breda, 1999).

Devido a essa orientação, voltada ao usuário indicada pelo Asobat, que foi publicado, em 1970, pelo (APB), o Pronunciamento n. ${ }^{\circ}$ (APB 4), sob o título Basic Concepts and Accounting Principles Underlying Financial Statements of Business Enterprises. O referido pronunciamento reafirmou o fornecimento de informações financeiras úteis para tomada de decisões econômicas como sendo o objetivo da Contabilidade. Adicionado a isto, o APB 4 delineou diversos objetivos qualitativos para que esse objetivo pudesse ser alcançado, tais como a necessidade de a informação ser relevante, compreensível, oportuna, e assim por diante (Accounting Principles Board [APB], 1970).

Adicionado a isso, verifica-se que o pronunciamento refletia os princípios e teve alta aceitação (Deegan \& Unermam, 2011). Ele estava organizado da seguinte maneira: 1) Objetivos, divididos em gerais e qualitativos (relevância, oportunidade); 2) Aspectos Básicos, tais como entidade em funcionamento; 3) Elementos básicos (ativos; passivos); 4) Princípios, divididos em a) gerais, b) convenções modificadoras - destaque para presença do Conservadorismo; c) operacionais amplos; e d) detalhados (APB, 1970).

Segundo o pronunciamento APB 4, os princípios de convenções modificadoras, no qual se enontra o Conservadorismo, são aplicados por meio de normas geralmente aceitas, sendo assim um meio de substituir o julgamento coletivo dos profissionais pelo julgamento de um contador individual.

O supracitado pronunciamento dispõe que, em um contexto em que existem incertezas significativas de mensuração de ativos e passivos, o Conservadorismo consiste no fato de que os administradores, investidores e contadores preferem optar pela possibilidade de erros na mensuração subestimada ao invés de superestimar o resultado líquido e os ativos líquidos. Exemplifica o emprego do Conservadorismo quando na mensuração do estoque pelo menor valor entre o custo ou mercado e destaca que tais regras podem resultar numa divulgação de lucro líquido e ativo líquido em montantes menores do que aqueles que poderiam ser alcançados sem a utilização do princípio (APB, 1970).

Embora o APB 4 tenha recebido aceitação e não tenha causado controvérsia, algumas críticas eram direcionadas à classe contábil devido à ausência de um trabalho conceitual, além da demanda por normas contábeis para instituições financeiras. Dessa forma, o AICPA criou dois grupos de estudos, Trueblood Committee (responsável pelos objetivos das demonstrações financeiras) e Wheat Committee (responsável pelas discussões que envolvem os princípios contábeis) (Niyama \& Silva, 2011).

O Trueblood Committee, que tratou dos objetivos das demonstrações financeiras, em 1973, emitiu seu relatório denominado Report of the Study Group on the Objectives of Financial Statements, expressando 12 (doze) objetivos e 7 características da informação financeira, a saber: 1) relevância e materialidade; 2) forma e substância; 3) confiabilidade; 4) livre de tendência; 5) comparabilidade; 6) consistência, e 7) compreensibilidade.

Enquanto que o Wheat Committee, publicou um parecer propondo uma nova estrutura para o estabelecimento de normas e padrões contábeis, sugerindo a extinção da APB e a criação do Financial Accounting Standard Board (Fasb), para desenvolver os princípios de contabilidade generalizadamente aceitos (Niyama \& Silva, 2011).

O Fasb, criado em 1973, "consiste em uma instituição privada que visa identificar novos eventos econômicos, discutir formas diferenciadas para sua contabilização e decidir pela considerada mais apropriada" (Teixeira et al., 2009, p. 76).

Assim que fora constituído, engrenou o projeto de EC, e, em 1978, emitiu a Statements of Financial Accounting Concepts (SFAC) n. ${ }^{\circ}$ : Objetivos dos relatórios financeiros por Empresas, sendo seguidos de outros pronunciamentos influenciados pelo Asobat e APB 4, de maneira que o enfoque da normatização contábil foi transferido de princípios para padrões (Deegan \& Unermam, 2011). O próprio APB 4 define Conservadorismo na perspectiva de subavaliar os ativos e superavaliar os passivos. Posteriormente, teve a publicação do SFAC 2 (Qualitative Characteristics of Accounting Information, adotando partes consideráveis do APB 4, quanto aos objetivos qualitativos, cujo nome fora substituído por características qualitativas, foram considerados praticamente na íntegra, contudo, traz o Conservadorismo no sentido de Prudência, como destacado no seu parágrafo 92. 
De acordo com Zeff (1999, p. 109), "em contraste com Asobat e o relatório Trueblood, a diretoria vislumbrou um papel de "Conservadorismo", embora constrangido" e afirmou em seu parágrafo 92 do SFAC que: "há lugar para uma convenção como a do Conservadorismo, que significa Prudência, uma vez que as atividades de negócio e as atividades econômicas são cercadas pela incerteza”, porém, ressalta-se que essa necessidade tem que ser aplicada com cuidado.

O SFAC 2 afirma, porém, que o Conservadorismo tende a entrar em conflito com características qualitativas e cita, como exemplo, a neutralidade. Declara que a presença desse componente está enraizada nos relatórios financeiros, apesar dos esforços para mudar esse estado, e que surgiu em uma época em que o balanço era considerado principal demonstração e seus principais usuários externos (banqueiros e outros credores) desejavam a presença do Conservadorismo, uma vez que, quanto maior a subavaliação de ativos, maior a margem de segurança desses ativos dados em garantia de empréstimos ou outras dívidas (Financial Accounting Standards Board [FASB] (1980, parágrafo 93).

Em seu parágrafo 94, ressalta, que subavaliar os ativos ou superavaliar os passivos em um período, geralmente, acarretaria na superavaliação do desempenho financeiro em períodos posteriores. Destaca, também, que o Conservadorismo é uma reação prudente em meio à incerteza para tentar garantir que essas incertezas e riscos, inerentes às situações de negócios, sejam consideradas adequadamente, de maneira que, se duas estimativas de valores a serem recebidos ou pagos no futuro são igualmente prováveis, o Conservadorismo dita utilizar a estimativa menos otimista. No entanto, se dois valores não são igualmente prováveis, o Conservadorismo não necessariamente dita utilizar a quantidade mais pessimista, em vez da mais provável (parágrafo 95). Em consonância com o exposto, pode-se considerar que este posicionamento do Fasb em relação à Prudência, viria influenciar, posteriormente, na retirada deste termo da EC do Iasb.

\subsection{Estrutura conceitual para relatórios financeiros lasb}

No que concerne ao desenvolvimento da EC do Iasb, verifica-se uma forte influência da EC do Fasb, devido aos Estados Unidos da América possuirem posição relevante nos mercados mundiais e suas normas influenciarem as demais nações (Niyama \& Silva, 2011).

Alguns fatos notórios marcaram o desenvolvimento do Iasb. A criação da Comunidade Econômica Europeia (CEE) que, posteriormente, tornou-se a União Europeia, objetivou o estreitamento das relações comerciais, de modo que países europeus passassem a compartilhar o mesmo mercado, o que acarretou no aumento da necessidade de uniformizar as demonstrações contábeis (Paulo, 2002).

Em 1959, o presidente do Instituto de Contadores Licenciados dos Países Baixos, propôs o estabelecimento de normas internacionais. Isso diante de um contexto em que o crescimento do mercado e o avanço das multinacionais resultou no desenvolvimento internacional da Contabilidade, de maneira que blocos econômicos, a exemplo da União Europeia, começaram a ser formados no intuito de discutir parâmetros em comum nas áreas econômicas e políticas (Niyama \& Silva, 2011).

Diante dessa conjuntura, foi criado, em 1961, um grupo de discussão e renovação de assuntos contábeis com a finalidade de auxiliar a Comunidade Europeia. Este, por sua vez, evoluiu e transformou-se, em 1973, no Internacional Accounting Standards Comittee (Iasc) que, no ano de 2000, tornaria-se o Internacional Accounting Standards Board (Iasb), órgão este que estuda padrões de contabilidade, com o objetivo de desenvolver um único conjunto de normas contábeis globais, de modo que as informações venham a ser transparentes e comparáveis.

Em 1975, foram editadas as Normas Internacionais de Contabilidade e criadas as Diretivas Gerais e Diretivas Comunitárias que tinham como propósito estabelecer normas comerciais que possuíam peso de lei em todos os países da União Europeia. Destaque para Diretiva n. ${ }^{\circ} 4$ (1978), que, ao dispor sobre os princípios contábeis utilizados nos países integrantes da União Europeia, apresentaram a Prudência (Paulo, 2002; Barth, Landsman \& Lang, 2008). 
No ano de 1989 foi publicada pelo, até então, Iasc, uma EC para Elaboração e Apresentação das Demonstrações Contábeis, intitulada de Framework for the Preparation and Presentation of Financial Statements. Os pronunciamentos do Iasc eram denominados de International Accounting Standards (IAS), posteriormente, quando se tornou Iasb, os pronunciamentos passaram a ser denominados de International Financial Reporting Standards (IFRS).

\subsection{Panorama atual da estrutura conceitual para relatórios-financeiros}

O início do século XXI foi marcado por escândalos contábeis em empresas conceituadas e de grande porte da economia americana, a exemplo da Enron, Worldcom e a empresa de auditoria Arthur Andersen, demonstrando fragilidade no conjunto de normas contábeis. Quando o público tomou conhecimento de tais acontecimentos, investidores reclamaram por medidas ao Governo Americano, que permitissem maior transparência nas demonstrações financeiras. Dentre as consequências advindas deste fato, pode-se citar a promulgação da Lei Sarbanes-Oxley (SOX), cujo propósito consiste em garantir aos investidores maior proteção, estabelecendo confiabilidade nas informações fornecidas pelas empresas (Teixeira et al., 2009), além de iniciar um debate sobre normas baseadas em regras ou em princípios.

Em vista deste acontecimento, os EUA ficaram pressionados a adotar os padrões internacionais de elaboração das demonstrações financeiras. De maneira que, no ano de 2002, o lasb e o Fasb decidiram desenvolver um trabalho conjunto, com o objetivo de que as normas contábeis do Iasb e do Fasb seriam de tal natureza comparável e que o órgão americano acabaria por, finalmente, adotar as IFRS e, assim, haveria um conjunto de normas de contabilidade (IFRS), que seriam utilizadas mundialmente (Deegan \& Unermam, 2011), permitindo aos investidores a tomada de decisão em um mercado de capital global (Barth, Landsman \& Lang, 2012)

Em julho de 2006, o Iasb e o Fasb publicaram, conjuntamente, um DP intitulado: "Preliminary Views on an improved Conceptual Framework for Financial Reporting: The Objective of Financial Reporting and Qualitative Characteristics of Decision-useful Financial Reporting Information" (IASB, 2006). O DP consiste em um documento emitido com a finalidade de obter pontos de vista iniciais e comentários sobre o que o público considera a respeito de uma série de assuntos (IASB, 2013).

Em 2008, o Fasb e o Iasb, após receberem cerca de 200 respostas ao DP emitiram, em um Exposure Draft dos capítulos sobre os objetivos e características qualitativas (Deegan \& Unermam, 2011). Posteriormente, houve a emissão do pronunciamento propriamente dito, em que alterações propostas, emitidas neste, parecem ter sido fortemente influenciadas pelos EUA, de maneira que se observou uma ênfase dada ao uso da informação contábil por participantes do mercado de capitais. A exemplo dessa afirmação, tem-se que, dentre as mudanças estabelecidas na EC, após o trabalho conjunto, foi a retirada do termo Prudência, quando se sabe que o Fasb, com o objetivo de atingir a "neutralidade da informação", procura impedir o Conservadorismo (Watts, 2003).

No ano de 2010, o Iasb e o Fasb emitiram uma revisão de duas seções da EC sobre os objetivos das demonstrações contábeis para fins gerais e as características qualitativas da informação financeira útil e, ainda no mesmo ano, suspenderam, temporariamente, os futuros trabalhos sobre a EC, devido à urgência de trabalhar em outros projetos, no rescaldo da crise financeira (IASB, 2013). Como resultado desse trabalho, o Fasb emitiu, em setembro de 2010, o SFAC 8, referindo-se aos capítulos 1 e 3 da EC do Iasb.

O Iasb, por sua vez, realizou, no ano seguinte, uma consulta pública em que se verificou uma necessidade em priorizar o término da EC. Desse modo, em 2012, o Iasb reinicia suas deliberações para desenvolver a EC, dessa vez em um único projeto e dentro de um período de tempo desafiador, deixando de lado a primeira abordagem dividida em fases, porém, sem o Fasb (IASB, 2013).

Portanto, no ano de 2013, o Iasb lançou, sem a participação do Fasb, o DP no intuito de obter opiniões quanto à reformulação da EC. Um dos questionamentos proferidos no supracitado DP é com relação a alteração realizada em 2010, sobre a exclusão do termo Prudência. Isso porque os parágrafos 35-38 da EC pré-2010 defendiam que, para ser confiável, a informação deveria ser neutra, e, assim, livre de propensões. Adicionalmente argumentava que, a título de Prudência, deve-se ter cuidado no exercício de jul- 
gamentos inevitáveis ao fazer as estimativas necessárias sob as condições de incerteza, para que, assim, os ativos ou receitas não sejam maximizadas e que passivos ou despesas não sejam amenizadas (IASB, 2013).

A retirada do termo Prudência foi justificada pelo Iasb, não a incluindo como um aspecto da representação fiel, pois estaria sendo contraditória à neutralidade, de maneira que conduziria a inclinações na elaboração das demonstrações financeiras. Adicionado a isso, tem-se o entrave de que, ao subestimar os ativos ou superestimar os passivos em um período, conduziria, geralmente, na superavaliação do desempenho financeiro em períodos posteriores (IASB, 2013). Segundo Gebhardt, Mora e Wagenhofer (2014), a decisão do Iasb em retirar o termo Prudência foi tão controversa quanto à retirada do termo destaque da administração, além de que a Prudência prevalecia em muitos IFRS e inclusive em novas IFRS.

O que se observa são as contraposições à retirada do termo, defendendo sua inclusão e justificando que ao utilizar-se do Conservadorismo estimativas demasiadamente otimistas da administração seriam combatidas. Além de que é argumentado que a referida retirada poderia resultar no reconhecimento de ativos e ganhos cuja existência é duvidosa, bem como o não reconhecimento de possíveis passivos e perdas, e aumento do uso de mensurações de valor atual, o que inclui o valor justo, podendo ser visto como difíceis de se verificar e predispostos ao erro (IASB, 2013).

Adicionado a esta discussão, tem-se que a EC representa um papel subordinado em relação às IFRS existentes, ou seja, se existir conflito entre uma norma e a EC, a norma deve prevalecer. Diante disso, tem-se a retirada da Prudência das características qualitativas, mas o que se observa é a presença do Conservadorismo em muitos IFRS existente e inclusive em novas IFRS (Gebhardt, Mora, \& Wagenhofer, 2014).

Vale ressaltar que, para fins deste estudo, os termos Prudência e Conservadorismo são considerados sinônimos, tendo em vista que o termo "Prudência" foi apresentado como uma alternativa para o termo Conservadorismo, que foi largamente utilizado como uma adaptação da doutrina contábil anglo-saxônica, que era aplicada como uma convenção entre contadores" (Andrade, 2009, p. 39).

\subsubsection{Expectativa dos respondentes}

O desenvolvimento das normas do Iasb acontece por meio de um processo de consulta pública internacional, cujo fluxograma é descrito na Imagem 1.

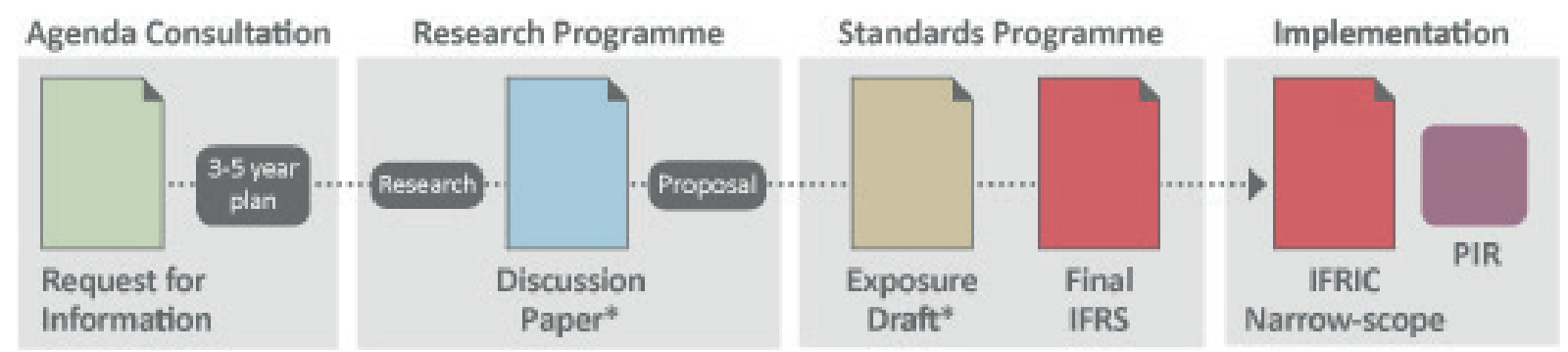

Figura 1. Processo de elaboração de normas do IASB

Fonte: IASB (2015).

Contudo, o desenvolvimento se dá em 6 fases. Inicia com a definição da agenda, em seguida, após incluir na agenda, é planejado o projeto. Neste caso o Iasb decide se desenvolverá sozinho ou em parceria com outra instituição, além de definir o grupo que coordenará o projeto. No segundo momento, é desenvolvido e publicado o Discussion Paper, que inclui uma visão geral do tema e uma chamada para comentários da comunidade internacional. 
A terceira fase é o desenvolvimento e publicação do Exposure Draft (ED), que leva em consideração os comentários (CL) recebidos, mas se apresenta em forma de uma minutada norma, sendo divulgada e aberta a novos comentários dos interessados. Após analisar as críticas ao ED, é emitida a norma final (IFRS Final). Por fim, o lasb auxilia com o entendimento da norma e o impacto desta (IASB, 2015).

Dentro desse processo, a participação dos constituintes do Iasb é mais facilmente observada na audiência pública do Discussion Paper (DP) e Exposure Draft (ED). O DP não é obrigatório, mas o Iasb normalmente publica quando se trata de um tópico novo e solicita comentários iniciais de seus constituintes. $\mathrm{O}$ resultado dessa etapa pode converter-se em projeto de pesquisa a ser conduzido por outro órgão normativo de contabilidade ou, no primeiro estágio de um projeto (agenda) ativo, conduzido pelo Iasb (IASB, 2012).

Com base nesta forma de desenvolvimento, cada grupo de agentes interessados na Contabilidade buscará influenciar a norma, por meio dos comentários enviados, visando maximizar sua própria utilidade.

Independentemente de ter publicado o DP, o ED é o principal meio de consulta pública do lasb, pois é uma proposta específica (minuta) de procedimento contábil em forma de norma. Por isso, muitas pesquisas sobre a regulação contábil se concentram nas cartas de comentários encaminhadas pelos diversos agentes interessados sobre o ED em análise (Saemann, 1999; Giner \& Arce, 2012; Larson \& Herz, 2013). Assim, este trabalho analisa os DPs sobre EC, especificamente no tocante à eliminação, ou não, da Prudência.

As pesquisas sobre regulação da Contabilidade têm como principal preocupação compreender como as forças de lobby atuam no processo de emissão das normas contábeis, buscando identificar o nível de eficiência desses esforços para atingir os propósitos dos lobistas. $\mathrm{Na}$ análise da Prudência, pode-se considerar que os grupos de agentes interessados tenham opiniões distintas, devido as suas características particulares e interesses sobre o tema. Assim, diante do exposto, têm-se as seguintes hipóteses de pesquisa:

H1. Os reguladores da Contabilidade apresentaram opiniões diferentes entre si quanto à Prudência nas cartas-comentários sobre a Prudência.

H2. Os agentes interessados apresentaram opiniões diferentes dos demais agentes quanto à Prudência nas cartas-comentários sobre a Prudência.

\section{Procedimentos Metodológicos}

O universo da pesquisa é composto pelas cartas-comentários (Comment Letters) enviadas ao Iasb, como resposta aos DPs emitidos em 2006 e 2013. Cabe lembrar que o primeiro DP versou sobre o Objetivo e Características Qualitativas dos Relatórios Financeiros, ao passo que o segundo DP discute aspectos relacionados à emissão de uma Estrutura Conceitual para Relatórios Financeiros revisada.

Dentre os assuntos discutidos no DP, referente ao segundo DP, estão: elementos dos relatórios financeiros; definição de ativo e passivo; diferença entre passivo e patrimônio líquido. Aliado a isto, possuía questionamentos acerca dos capítulos 1 e 3 da EC (objetivos e características qualitativas), cuja finalização ocorreu em 2010 como resultado do primeiro DP, a fim de que os respondentes opinassem acerca da necessidade de um novo debate sobre tais capítulos. Dessa forma, era esperado um maior número de respostas sobre a Prudência e/ou Conservadorismo no primeiro momento, tendo em vista que as alterações das características qualitativas foram sugeridas no primeiro momento.

As cartas enviadas ao Iasb, nos dois períodos mencionados, perfazem 420, das quais 179 correspondem ao primeiro DP analisado (2006), ao passo que 241 correspondem ao segundo DP (2013). Na Tabela 1 é possível verificar as amostras obtidas a partir do universo das 420 cartas. Vale destacar que o acesso às cartas-comentários foi realizado por meio do site do Iasb. 
Tabela 1

Amostra da Pesquisa

\begin{tabular}{|c|c|c|c|c|c|c|}
\hline \multirow{2}{*}{ Item } & \multicolumn{2}{|c|}{ DP 2006} & \multicolumn{2}{|c|}{ DP 2013} & \multicolumn{2}{|c|}{ Soma } \\
\hline & $\mathrm{N}$ & $\%$ & $\mathrm{~N}$ & $\%$ & $\mathrm{~N}$ & $\%$ \\
\hline Total de cartas enviadas & 179 & 100,0 & 241 & 100,0 & 420 & 100,0 \\
\hline $\begin{array}{l}\text { Total de cartas onde os termos Prudence e/ou Conservatism são } \\
\text { mencionados }\end{array}$ & 55 & 30,7 & 121 & 50,2 & 176 & 41,9 \\
\hline $\begin{array}{l}\text { Total de cartas que não mencionam os termos Prudence e/ou } \\
\text { Conservatism, porém suscitam uma discussão indireta a respeito dos } \\
\text { termos }\end{array}$ & 48 & 26,8 & 69 & 28,6 & 117 & 27,9 \\
\hline Amostra final & 103 & 57,5 & 190 & 78,8 & 293 & 69,8 \\
\hline
\end{tabular}

Foi realizada uma coleta manual nas 420 cartas disponíveis, pelos termos Prudence e/ou Conservatism. Como resultado da análise, obtiveram-se os seguintes números: a) para as cartas enviadas no primeiro DP analisado (2006), alcançou-se um número de 55 cartas que continham um dos termos buscados; b) para as cartas enviadas no segundo DP analisado (2013) obtiveram-se 121 cartas que dispunham de um dos termos pesquisados. Dessa forma, obtiveram-se 176 cartas-comentários que possuem os termos Prudence e/ou Conservatism.

Adicionalmente, para aquelas cartas em que não foram identificadas nenhum dos dois termos, realizou-se uma análise de conteúdo de forma mais analítica a fim de identificar se, porventura, existia alguma discussão a respeito dos termos em questão. Após a referida análise de conteúdo, detectaram-se mais 117 cartas, 48 CLs referentes ao primeiro DP e 69 CLs referentes ao segundo DP (2013).

Uma vez selecionadas as cartas-comentários, estas foram segregadas por grupo de interesses e por continente a qual o respondente pertence.

Verificaram-se também os respondentes que manifestaram suas opiniões nos dois DPs analisados (2006 e 2013), totalizando 69 respondentes. Estes, por sua vez, foram emparelhados, aplicando-se a Análise de Kappa, com a finalidade de medir o grau de concordância entre eles. Pela análise de Kappa, os valores são assumidos entre um negativo (-1) e um positivo $(+1)$, em que 1 representa total concordância; zero indica que houve apenas concordância ao acaso; e valores inferiores a zero sugerem que a concordância ao acaso foi menor do que a esperada (Landis \& Koch, 1977).

\section{Apresentaçao e Análise dos Resultados}

\subsection{Estatística descritiva}

Com o objetivo de facilitar a análise, consideram-se as cartas-comentários (CLs) enviadas referentes ao primeiro DP do EC (DP 2006), e as cartas enviadas para o segundo DP (DP 2013).

Na Tabela 2, pode-se observar a quantidade de respondentes, de modo que estão segregados por continente e grupo a qual pertencem, considerando sua classificação entre agentes interessados da Contabilidade. Estes, por sua vez, foram divididos da seguinte forma: 1) Reguladores (REG), constituído por entidades reguladoras nacionais e internacionais; 2) Preparadores das Informações (Pinf), composto por empresas de contabilidade, contadores autônomos e contadores funcionários de empresas; 3 ) Academia (ACD), representado pelos professores e pesquisadores; 4) Auditores (AUD) formados por empresas de auditorias e auditores independentes; 5) Entidades Representativas (Erep) equivalentes a entidades que representam profissionais da contabilidade, para contadores públicos e públicos certificados e 6) Instituições Financeiras (Ifina) composta por instituições financeiras. 
Tabela 2

Número de respondentes por localidade e grupo

\begin{tabular}{|c|c|c|c|c|c|c|c|c|}
\hline \multirow{3}{*}{ Grupos interessados } & \multicolumn{8}{|c|}{ Continente } \\
\hline & \multirow{2}{*}{ África } & \multicolumn{2}{|c|}{ América } & \multirow{2}{*}{ Ásia } & \multirow{2}{*}{ Europa } & \multirow{2}{*}{ Oceania } & \multicolumn{2}{|c|}{ Total } \\
\hline & & Anglo-Saxônica & Latina & & & & (f) & $(\%)$ \\
\hline REG & 0 & 11 & 4 & 13 & 31 & 9 & 68 & 16 \\
\hline PINF & 3 & 24 & 7 & 6 & 63 & 7 & 110 & 26 \\
\hline $\mathrm{ACD}$ & 1 & 20 & 2 & 4 & 21 & 7 & 55 & 13 \\
\hline AUD & 0 & 3 & 0 & 0 & 16 & 2 & 21 & 5 \\
\hline EREP & 6 & 17 & 2 & 11 & 21 & 6 & 63 & 15 \\
\hline IFINA & 0 & 22 & 3 & 4 & 71 & 3 & 103 & 25 \\
\hline Total (f) & 10 & 97 & 18 & 38 & 223 & 34 & 420 & 100 \\
\hline Total (\%) & 2,4 & 23,1 & 4,3 & 9 & 53,1 & 8,1 & & \\
\hline
\end{tabular}

Fonte: resultados da pesquisa.

No que diz respeito ao continente americano, sua divisão em América Anglo-Saxônica e América Latina foi considerada, com a finalidade de estabelecer melhor comparação, dadas as suas diferenças culturais.

$\mathrm{Na}$ Tabela 2, pode-se observar que pouco mais da metade das cartas enviadas ao Iasb provém do continente europeu (53,1\%), seguido da América Anglo-Saxônica com 23\% de participação. Quanto aos grupos de interessados, destacam-se os Preparadores das Informações (Pinf) e as Instituições Financeiras (Ifina) com $26 \%$ e $25 \%$ de participação, respectivamente, ao passo que a Academia (ACD) contribuiu com apenas $13 \%$ das respostas. A maior participação dos preparadores (Pinf e Ifina), que representa aproximadamente $51 \%$ do total das CLs analisadas, também é observada nas pesquisas anteriores que analisam os comentários aos ED emitidos pelo Iasb, como por exemplo em Giner \& Arce (2012), Larson \& Herz (2013) e Tavares, Anjos, Paulo, \& Carter (2013). Essa grande participação pode ser explicada simplesmente pelo fato de que o número de empresas existentes nos diversos países é infinitamente maior que o número dos demais grupos interessados.

No que concerne à presença dos termos Prudence e/ou Conservatism nas cartas, é possível contemplar na Tabela 3 que o termo Prudence é mencionado em 162 cartas, sendo este mais utilizado do que o termo Conservatism (Tabela 4), presente em apenas 73 cartas.

Tabela 3

Presença do termo Prudence nas cartas-comentários

\begin{tabular}{cccccccc}
\hline \multirow{2}{*}{ Ano } & \multicolumn{2}{c}{ Sim } & \multicolumn{3}{c}{ Não } & \multicolumn{2}{c}{ Total } \\
\cline { 2 - 7 } & $(\mathrm{f})$ & $(\%)$ & $(\mathrm{f})$ & $(\%)$ & (f) & 179 \\
\hline 2006 & 43 & 24 & 136 & 76 & 241 \\
\hline 2013 & 119 & 49 & 122 & 51 & 61 & 420 \\
\hline Total & 162 & 39 & 258 & 61 &
\end{tabular}

Fonte: resultados da pesquisa.

É possível contemplar, também, que a presença dos termos é mais identificada nas cartas enviadas no segundo DP, em comparação com as cartas enviadas no primeiro DP. Esse resultado sugere que os diferentes agentes da contabilidade tornaram-se mais ativos nas discussões das novas normas ou nas revisões dos documentos emitidos pelo lasb nos últimos tempos. 
Tabela 4

Presença do termo Conservatism nas cartas-comentários

\begin{tabular}{cccccccc}
\hline \multirow{2}{*}{ Ano } & \multicolumn{2}{c}{ Sim } & \multicolumn{3}{c}{ Não } & \multicolumn{2}{c}{ Total } \\
\cline { 2 - 8 } & (f) & $(\%)$ & (f) & (\%) & (f) \\
\hline 2006 & 34 & 19 & 145 & 81 & 179 \\
\hline 2013 & 39 & 16 & 202 & 84 & 241 \\
\hline Total & 73 & 17 & 347 & 83 & 420 \\
\hline
\end{tabular}

Fonte: resultados da pesquisa.

Tabela 5

Presença dos termos Prudence e Conservatism nas cartas-comentários

\begin{tabular}{cccccccc}
\hline \multirow{2}{*}{ Ano } & \multicolumn{2}{c}{ Sim } & \multicolumn{2}{c}{ Não } & \multicolumn{2}{c}{ Total } \\
\cline { 2 - 8 } & $(\mathrm{f})$ & $(\%)$ & $(\mathrm{f})$ & $(\%)$ & (f) \\
\hline 2006 & 22 & 12 & 157 & 88 & 179 \\
\hline 2013 & 37 & 15 & 204 & 84 & 241 \\
\hline Total & 59 & 14 & 361 & 86 & 420 \\
\hline
\end{tabular}

Fonte: resultados da pesquisa.

Algumas cartas possuíam a presença de ambos os termos (Tabela 5). Deste modo, o total de cartas analisadas foi de 176, pois, de alguma maneira, possuíam a presença de pelo menos um dos termos. Foi realizada a leitura de todas as 176 cartas, de modo a identificar a opinião dos respondentes sobre a defesa, ou não, do termo Prudência e/ou Conservadorismo na EC.

Apesar de 176 cartas analisadas citarem os termos Prudence e/ou Conservatism, somente 117 destas emitiram uma opinião definida sobre o tema em discussão. Na Tabela 6, é possível verificar que cerca de 91 respondentes (78\%) são favoráveis à inclusão do termo "Prudência" na EC, ao passo que outros 26 respondentes entendem que a Prudência não deve estar presente na Estrutura Conceitual.

Tabela 6

Respondentes a favor da utilização do termo Prudência na EC

\begin{tabular}{cccccccc}
\hline \multirow{2}{*}{ Ano } & \multicolumn{2}{c}{ Sim } & \multicolumn{3}{c}{ Não } & \multicolumn{2}{c}{ Total } \\
\cline { 2 - 7 } & (f) & $(\%)$ & (f) & (\%) & (f) \\
\hline 2006 & 37 & 77 & 11 & 23 & 48 \\
\hline 2013 & 54 & 78 & 15 & 22 & 69 \\
\hline Total & 91 & 78 & 26 & 22 & 117 \\
\hline
\end{tabular}

Fonte: resultados da pesquisa.

No que se refere aos grupos interessados na Contabilidade, observa-se na Tabela 7 que os Acadêmicos (92,7\%), os Preparadores das Informações Contábeis (87,1\%) e os Auditores (83,3\%) constituem os grupos mais favoráveis a inserção do termo "Prudência" na EC, sendo que o grupo que mais defendeu a exclusão do termo foi aquele formado pelos Reguladores (66,7\%). Porém, pode ser observado que em todos os grupos de interessados os emitentes da cartas-comentários foram favoráveis à inclusão da Prudência na Estrutura Conceitual. O grupo dos Reguladores foi o único grupo em que houve uma mudança relevante na opinião sobre a inclusão, ou não, da Prudência, passando a defender mais a Prudência no segundo DP. 
Tabela 7

Opinião sobre a Prudência na EC segregados por grupo

\begin{tabular}{lccccccc}
\hline Respostas & REG & PINF & AUD & ACD & IFINA & EREP & Total \\
\hline \multicolumn{7}{c}{ Painel A - Resposta ao ED 2006 } \\
\hline Sim & $4(50)$ & $9(81,8)$ & $1(100)$ & $11(91,7)$ & $8(80)$ & $4(66,7)$ & $37(77,1)$ \\
\hline Não & $4(50)$ & $2(18,2)$ & $0(0)$ & $1(8,3)$ & $2(20)$ & $2(33,3)$ & $11(22,9)$ \\
\hline Total & $8(100)$ & $11(100)$ & $1(100)$ & $12(100)$ & $10(100)$ & $6(100)$ & $48(100)$ \\
\hline \multicolumn{7}{c}{ Painel B - Resposta ao ED 2013} \\
\hline Sim & $8(80)$ & $18(90)$ & $4(80)$ & $2(100)$ & $12(66,7)$ & $10(71,4)$ & $54(78,3)$ \\
\hline Não & $2(20)$ & $2(10)$ & $1(20)$ & $0(0)$ & $6(33,3)$ & $4(28,6)$ & $15(21,7)$ \\
\hline Total & $10(100)$ & $20(100)$ & $5(100)$ & $2(100)$ & $18(100)$ & $14(100)$ & $69(100)$ \\
\hline \multicolumn{7}{c}{ Painel C - Amostra Total } \\
\hline Sim & $12(66,7)$ & $27(87,1)$ & $5(83,3)$ & $13(92,9)$ & $20(71,4)$ & $14(70)$ & $91(77,8)$ \\
\hline Não & $6(33,3)$ & $4(12,9)$ & $1(16,7)$ & $1(7,1)$ & $8(28,6)$ & $6(30)$ & $26(22,2)$ \\
\hline Total & $18(100)$ & $31(100)$ & $6(100)$ & $14(100)$ & $28(100)$ & $20(100)$ & $117(100)$ \\
\hline
\end{tabular}

Legenda: Reguladores (REG). Preparadores das Informações (PINF). Academia (ACD). Auditores (AUD).

Entidades Representativas (EREP). Instituições Financeiras (IFINA). Valor absoluto (\%).

Fonte: resultados da pesquisa.

$\mathrm{Na}$ análise sobre a perspectiva geográfica (Tabela 8), observa-se que em todos continentes mais de $80 \%$ dos respondentes foram a favor do termo Prudência/Conservadorismo, ao passo que a América Anglo-Saxônica é o local que concentra mais respondentes que opinam contra o termo na EC.

Foi exatamente nos respondentes originados da América Anglo-Saxônica que se observa uma mudança significativa de perfil de resposta. No primeiro DP (DP 2006), é observado que em suas cartas, esses opinaram fortemente a favor da Prudência (75\%), entretanto na consulta seguinte (DP 2013), somente $42,9 \%$ são favoráveis.

Tabela 8

Opinião sobre a Prudência na EC segregados por Continente

\begin{tabular}{|c|c|c|c|c|c|c|c|}
\hline Respostas & África & $\begin{array}{c}\text { América Anglo- } \\
\text { Saxônica }\end{array}$ & $\begin{array}{c}\text { América } \\
\text { Latina }\end{array}$ & Ásia & Europa & Oceania & Total \\
\hline \multicolumn{8}{|c|}{ Painel A - Resposta ao ED 2006} \\
\hline Sim & $4(100)$ & $9(75)$ & $2(50)$ & $5(100)$ & $17(77,3)$ & $0(0)$ & $37(77,1)$ \\
\hline Não & $0(0)$ & $3(25)$ & $2(50)$ & $0(0)$ & $5(22,7)$ & $1(100)$ & $11(22,9)$ \\
\hline Total & $4(100)$ & $12(100)$ & $4(100)$ & $5(100)$ & $22(100)$ & $1(100)$ & $48(100)$ \\
\hline \multicolumn{8}{|c|}{ Painel B - Resposta ao ED 2013} \\
\hline Sim & $0(0)$ & $6(42,9)$ & $6(100)$ & $8(80)$ & $26(83,9)$ & $8(100)$ & $54(78,3)$ \\
\hline Não & $0(0)$ & $8(57,1)$ & $0(0)$ & $2(20)$ & $5(16,1)$ & $0(0)$ & $15(21,7)$ \\
\hline Total & $0(0)$ & $14(100)$ & $6(100)$ & $10(100)$ & $31(100)$ & $8(100)$ & $69(100)$ \\
\hline \multicolumn{8}{|c|}{ Painel C - Amostra Total } \\
\hline Sim & $4(100)$ & $15(57,7)$ & $8(80)$ & $13(86,7)$ & $43(81,1)$ & $8(88,9)$ & $91(77,8)$ \\
\hline Não & $0(0)$ & $11(42,3)$ & $2(20)$ & $2(13,3)$ & $10(18,9)$ & $1(11,1)$ & $26(22,2)$ \\
\hline Total & $4(100)$ & $26(100)$ & $10(100)$ & 15 (100) & $53(100)$ & $9(100)$ & $117(100)$ \\
\hline
\end{tabular}

Legenda: Valor absoluto (\%).

Fonte: resultados da pesquisa 
Esse resultado encontrado confirma a possível influência do Fasb, órgão estadunidense, sobre a retirada do termo da EC após o trabalho conjunto do Iasb com o Fasb. Isto porque o Fasb busca impedir o Conservadorismo, com o objetivo de atingir a "neutralidade da informação".

\subsection{Análise de Kappa}

A segunda parte da análise consistiu em comparar as opiniões dos mesmos respondentes que enviaram cartas-comentários aos DPs nos dois momentos analisados, totalizando 69 respondentes. Para efetuar tal comparação, foi utilizada a Análise de Concordância Kappa.

A Tabela 9 representa o comportamento das opiniões nos dois DPs analisados, destacando que, do total de 69 respondentes, nenhum deles permaneceu com a mesma opinião nos dois períodos analisados.

Tabela 9

Análise das opiniões de respondentes de 2006 e de 2013

\begin{tabular}{rcccccc} 
& & \multicolumn{3}{c}{ Concorda - DP 2013 } & \multirow{2}{*}{ Total } \\
\cline { 3 - 6 } & & Sim & Não & Sem Opinião & \\
\hline \multirow{3}{*}{ Concorda - DP 2006 } & Sim & 6 & 1 & 9 & 16 \\
\cline { 2 - 5 } & Não & 3 & 0 & 1 & 4 \\
\cline { 2 - 5 } & Sem Opinião & 17 & 5 & 37 & 49 \\
\hline
\end{tabular}

Fonte: resultados da pesquisa.

Observa-se que no primeiro DP o total de respondentes que preferiram não opinar a respeito da inclusão, ou não, do termo "Prudência/Conservadorismo" equivalem a 49, em que 27 desses permaneceram não opinando; no segundo DP, 17 respondentes tornaram-se a favor da inclusão do termo na EC e 5 mostraram opinião negativa quanto à referida inserção. No DP 2013, o número de respondentes baixou para 37 e entre estes estão alguns que se diziam a favor da inclusão do termo no primeiro período, mesmo com a Prudência sendo retirada da estrutura conceitual.

Tabela 10

Análise de Kappa entre os grupos de interesses na contabilidade

\begin{tabular}{lcccccccc}
\hline \multirow{2}{*}{ Defende Prudência } & \multicolumn{9}{c}{ Operadores } & \multirow{2}{*}{ Geral } \\
\cline { 2 - 7 } & REG & PINF & AUD & ACD & IFINA & EREP & \\
\hline Valor & -0.086 & -0.286 & -0.091 & -0.094 & 0.125 & 0.130 & 0.010 \\
\hline Número & 14 & 9 & 6 & 7 & 21 & 12 & 69 \\
\hline
\end{tabular}

Fonte: elaboração dos autores (2014).

A análise do índice Kappa (Tabela 10) foi utilizada por meio da escala proposta por Landis e Koch (1977). Foi estabelecido zero como uma concordância pobre; entre zero e vinte décimos é considerada como uma singela concordância; e, por fim, qualquer valor negativo indica que não há concordância. Sendo assim, é possível afirmar que não há concordância entre os seguintes grupos: Reguladores (REG); Preparadores das Informações (Pinf); Academia (ACD) e Auditores (AUD). Há uma singela concordância entre os grupos Entidades Representativas (Eerep) e as Instituições Financeiras (Ifina). Por fim, ao analisar todas as observações, sem estratificar, observou-se uma concordância fraca. 


\subsection{Análise das opiniões emitidas nas cartas-comentários}

Entre os que defendem a Prudência/Conservadorismo, pode-se observar notória divisão de opiniões no que diz respeito à similaridade dos termos "Prudência" e "Conservadorismo". Há quem defenda que os dois termos são equivalentes, entretanto, outra parcela aposta na diferença destes.

Essa referida parcela de respondentes afirma que "Prudência" possui um sentido de maior de cautela, principalmente quando há mais de um método de mensuração. Para estes, o Conservadorismo está atrelado à subavaliação dos ativos e receitas e superavaliação dos passivos e despesas. Contudo, observou-se que a maioria dos respondentes se referem exclusivamente ao termo "Prudência".

Os argumentos utilizados pelos respondentes que são a favor do termo Prudência na EC, bem como aqueles que são contra, estão em torno da incompatibilidade da Prudência com a neutralidade, que, porventura, também é o principal argumento utilizado pelo IASB para sustentar a eliminação do termo "Prudência" da EC.

A parcela que é favorável à inclusão do termo alega que não há incompatibilidade entre Prudência e neutralidade. No entanto, a parte contrária afirma a existência de tal incompatibilidade, corroborando os argumentos expostos pelo Iasb; outros apenas esboçam o posicionamento sem citar nenhuma justificativa adicional.

Contudo, alguns respondentes favoráveis à presença do termo na EC sugeriram que a Prudência poderia constar como uma restrição, similarmente ao custo-benefício da informação, em vez de uma característica qualitativa. Outras opiniões foram emitidas, como, por exemplo, a de que a ausência da Prudência eleva o risco moral. Os que são contrários ao termo afirmaram este como sendo de uso insensato, conduzindo a uma informação enviesada, enquanto outros evidenciaram a utilização de outros termos já existentes que exercem o papel da Prudência. Buscou-se, no Quadro 1, elencar as opiniões que foram além de concordar ou discordar com os pontos levantados no DP.

\section{Principais argumentos a favor e contra a inclusão da Prudência}

\begin{tabular}{|c|c|}
\hline Favoráveis & Desfavoráveis \\
\hline $\begin{array}{l}\text { “Conseguir mensurar e reportar sendo totalmente } \\
\text { objetivo é um mito. Não se tem imparcialidade, mesmo } \\
\text { que inconscientemente o preparador terá um viés. } \\
\text { Neutralidade não é possível sem Conservadorismo”. }\end{array}$ & $\begin{array}{l}\text { "Sendo a Prudência inconsistente com a neutralidade, } \\
\text { além de retirar da EC, também é preciso retirar } \\
\text { das normas específicas, como o caso do teste de } \\
\text { recuperabilidade, para que a retirada possa ser } \\
\text { consistente". }\end{array}$ \\
\hline
\end{tabular}

“Nós acreditamos que a forma em que a EC pré-2010 descreve Prudência, é suficiente para resolver todas as questões levantadas em se ter a Prudência na EC, como a contradição entre neutralidade e a subavaliação de ativos e superavaliação de passivos deliberadamente. Desta forma, sugerimos que a Prudência deve ser incluída na EC como exercício de cautela e não como um princípio de Conservadorismo".

"A demanda por Conservadorismo nos relatórios financeiros reflete o fato de que se há vantagens com informações privilegiadas, e que não se pode confiar que estas informações não serão utilizadas de maneira oportunista. A lição da Enron e tantos outros acontecimentos demonstram que este tipo de comportamento oportunista nunca está longe".

"Entendemos que o conceito comumente interpretado de Prudência/Conservadorismo, na prática, é inconsistente e com representação fidedigna".

Pode-se observar que os pontos favoráveis se alinham com o que foi levantado no SFAC 2, trazendo o Conservadorismo como forma de Prudência, baseando-se na incerteza inerente à elaboração dos relatórios. Contudo, os argumentos desfavoráveis giraram em torno de concordar com o que foi trazido no DP, o que dificultou encontrar outros pontos além da inconsistência com a representação fidedigna. 


\section{Considerações finais}

Ao inquirir sobre a utilização do termo "Prudência" na EC, constata-se a divergência de opiniões entre os grupos de interessados na contabilidade em face da utilização do supramencionado termo.

A revisão da literatura exposta na presente pesquisa evidenciou a importância da Prudência, entretanto, verificou-se uma considerável resignação na emissão de opiniões e apreciações acerca desta temática, por parte da grande maioria dos respondentes e emissores das cartas-comentários. Tal fato acarreta em um abrandamento nos debates e, consequentemente, no desinteresse e até mesmo abnegação na prossecução de suas discussões relevantes. É preciso, pois, a participação ativa dos agentes econômicos ligados à Contabilidade nesses debates, inclusive, maior envolvimento da Academia em tais discussões.

Com relação àqueles que evidenciaram suas opiniões, identificou-se que a maioria dos respondentes se mostrou favorável quanto à utilização do termo na EC. No primeiro Discussion Paper analisado, 27 dos respondentes foram a favor e 11 em contraposição, ao passo que, no segundo DP, 91 se mostraram a favor e 26 contrários.

Em linhas gerais, não existem diferenças significativas entre os grupos de interesses, sendo, em maior parte, favoráveis à inclusão da Prudência. No tocante à localização geográfica dos respondentes, aqueles da América Anglo-Saxônica que se posicionaram a favor da Prudência no DP de 2006 (75\%) mudaram de opinião, sendo que, no segundo DP sobre o tema, eles foram contra a inclusão do referido termo (57\%). Esse resultado pode ter sido influenciado pela tentativa da Fasb em retirar o termo Prudência/ Conservadorismo da sua Estrutura Conceitual. Outra justificativa para que os respondentes localizados na América Anglo-Saxônica sejam contrários à Prudência pode estar relacionada ao mercado financeiro local, caracterizado por um mercado de capitais desenvolvido e no qual o principal fornecedor de recursos é o investidor; enquanto que nos demais países a maior fonte de recursos financeiros é o mercado de crédito.

Quanto às justificativas entre os favoráveis e contrários à presença do termo, as considerações são diversas. Contudo, é possível frisar que muitos dos analisados não argumentaram nenhum ponto de vista adicional, apenas explicitaram suas opiniões entre concordar, ou não, quanto à presença do termo na EC.

Entre aqueles que expuseram suas justificativas, concentraram-se em torno do conflito existente entre Prudência e neutralidade. Os respondentes também se concentraram em opinar apenas sobre o termo Prudência utilizado pelo Iasb, sendo poucos os que se arriscaram a ensaiar sobre a distinção entre Prudência e Conservadorismo.

Por fim, atendendo ao objetivo principal da pesquisa, é possível sugerir que, apesar de o grupo das Instituições Financeiras e Entidades Representativas apresentarem uma singela concordância, quando não houve estratificação dos grupos, as opiniões não dispunham de concordância.

De modo geral, a discussão em torno desse assunto mostra-se relevante, uma vez que há necessidade de um discurso frutífero entre acadêmicos de Contabilidade, organismos de normalização, auditores, preparadores das demonstrações contábeis e todos os outros grupos mencionados no presente estudo. Adicionado a isso, haverá outras oportunidades de discussão em que se fará necessária uma participação ativa dos grupos, a fim de colaborar com o debate em torno de questões não completamente definidas.

O DP contém discussões sobre vários outros questionamentos importantes, como por exemplo, o debate em torno das bases de mensuração. Desta forma, o presente trabalho sugere para futuras pesquisas a análise das opiniões sobre outros pontos contidos na EC, bem como a identificação do grupo de operadores de contabilidade que mais influi nas decisões do Iasb, mediante análise das opiniões e decisões tomadas pelo Iasb. 


\section{Referências}

Accounting Principles Board (1970). Basic Concepts and Accounting Principles Underlying Financial Statements of Business Enterprises. New York: The American Institute of Certified Public Accountants.

Andrade, A. P. de. (2009) Princípios e Normas Contábeis. In: Ribeiro Filho, J. F, Lopes, J, \& Pederneiras, M. (Orgs.). Estudando Teoria da Contabilidade. São Paulo: Atlas.

Barth, M. E., Landsman, W. R. \& Lang, M. H. (2008). International Accounting Standards and Accounting Quality. Journal of Accounting Research. 46(3), pp. 467-498. doi: 10.1111/j.1475-679X.2008.00287.x

Barth, M. E., Landsman, W. R., Lang, M. H. \& Williams, C. (2012) Are IFRS-based and USGAAP-based accounting amounts comparable? Journal of Accounting and Economics. 54, pp. 68-93. doi:10.1016/j. jacceco.2012.03.001

Comitê de Pronunciamentos Contábeis (2011). Pronunciamento Conceitual Básico (R1): Estrutura Conceitual para Elaboração e Divulgação de Relatório Contábil-Financeiro. Brasília.

Deegan, C \& Unerman, J. Financial Accounting Theory. 2a ed. London: McGraw-Hill, 2011.

Financial Accounting Standards Board [FASB] (1980). Statement of Financial Accounting Concepts $n .^{\circ} 2$ : Qualitative Characteristics of Accounting Information. Norwalk: Financial Accounting Foundation.

Gebhardt, G, Mora, A, \& Wagenhofer, A. (2014). Revisiting the Fundamental Concepts of IFRS. Abacus: A Journal of Accounting, Finance and Business Studies, Sydney, 50(1), pp. 107-116. doi: 10.1111/abac.12024

Giner, B., \& Arce, M. (2012). Lobbying on accounting standards: evidence from IFRS 2 on share-based payments. European Accounting Review, 21(4), pp. 655-691. doi:10.1080/09638180.2012.701796

Godfrey, J, Hodgson, A, Holmes, S, \& Tarca, A. (2010). Accounting theory. $7^{\text {a }}$.ed New York: Wiley.

Hendriksen, E. S., \& Van Breda, M. F. (1999) Teoria da Contabilidade. trad. Antônio Zoratto Sanvicente. São Paulo: Atlas. Tradução de: Accounting theory.

International Accounting Standard Board [IASB] 2012. International Financial Reporting Standards IFRS (Red Book). London: IFRS Foundation.

International Accounting Standards Board [IASB] (2006). Preliminary Views on an improved Conceptual Framework for Financial Reporting: The Objective of Financial Reporting and Qualitative Characteristics of Decision-useful Financial Reporting Information DP/2006. London: IFRS Foundation.

International Accounting Standards Board [IASB] (2013). A review of the conceptual framework for financial reporting DP/2013/1. London: IFRS Foundation.

International Accounting Standards Board [IASB] (2015). Conceptual Framework. London: IFRS Foundation.

Landis, J. \& Koch, G. (1977). The Measurement of Observer Agreement for Categorical Data. Biometrics, 33(1), pp. 159-174.

Larson, R. K, \& Herz, P. J. (2013). A multi-issue/multi-period analysis of the geographic diversity of IASB comment letter participation. Accounting in Europe, 10(1), pp. 99-151. doi: $10.1080 / 17449480.2013 .772716$

Niyama, J. K, \& Silva, C. A. T. (2011) Teoria da contabilidade. 3. ed. São Paulo: Atlas, 2011.

Paulo, E. (2002) Comparação da Estrutura Conceitual da Contabilidade Financeira: Experiência Brasileira, Norte-americana e Internacional. João Pessoa. Dissertação (Mestrado em Ciências Contábeis) - Programa Multi-institucional de Pós-Graduação em Ciências Contábeis da Unb/UFPB/UFPE/UFRN.

Saemann, G. (1999). An examination of comment letters filed in the U.S. financial accounting standard setting process by institutional interest groups. Abacus, 35(1), pp.1-28. doi: 10.1111/1467-6281.00032 
Tavares, M. F. N., Anjos, L. C. M., Paulo, E., \& Carter, D. (2013). Contribuições ao exposure draft revenue from contracts with costumers: análise das opiniões das firmas sobre a obrigação de desempenho onerosa. Revista de Contabilidade do Mestrado em Ciências Contábeis da UERJ (Online), 18(2), pp. 81-99.

Teixeira, A. J. C, Costa, F. M. da, \& Galdi, F. C. (2009) Princípios e Normas Contábeis. In: Ribeiro Filho, J. F, Lopes, J, \& Pederneiras, M. (Org.). Estudando Teoria da Contabilidade. São Paulo: Atlas.

Watts, R. L. (2003) Conservatism in Accounting Part I: Explanations and Implications. Accounting Horizons, 17(3), pp. 207-221. doi: 10.2308/acch.2003.17.3.207

Zeff, S. A. (1999) The Evolution of The Conceptual Framework for Business Enterprises in The United States. Accounting Historians Journal, 26(2), pp. 89-131.

Zeff, S. A., \& John B. (2000) Canning: A View of His Academic Career. Abacus: A Journal of Accounting, Finance and Business Studies, Sydney, 36(1), pp. 4-39. doi: 10.1111/1467-6281.00052 